Bull. Mater. Sci., Vol. 35, No. 6, November 2012, pp. 1031-1038. (C) Indian Academy of Sciences.

\title{
Hydroxyapatite, a biomaterial: Its chemical synthesis, characterization and study of biocompatibility prepared from shell of garden snail, Helix aspersa
}

\author{
ANJUVAN SINGH \\ Department of Biotechnology and Biosciences, Lovely Professional University, Phagwara 144 411, India
}

MS received 10 February 2010; revised 20 July 2012

\begin{abstract}
The shell of garden snail (Helix aspersa) is basically made of calcium carbonate. An attempt is made to convert calcium carbonate of garden snail shell to hydroxyapatite. The snail shell was found to decompose within $850^{\circ} \mathrm{C}$ to all the carbonate phases. The calcined snail shells were then treated with acids followed by different chemicals in ammoniacal media maintaining proper stoichiometry to produce fine hydroxyapatite (HAP) as filter cake with a Ca/P molar ratio of 1.67. The dried HAP powder was extremely pure with a specific surface area of $15 \mathrm{~m}^{2} / \mathrm{g}$. The different characterization techniques were adopted both for calcined snail shell and HAP synthesized by X-ray diffraction (XRD), thermal analysis (DTA/TGA), Fourier transform infrared spectroscopy (FTIR) and scanning electron microscopy (SEM). The surface area and particle size of HAP powder prepared by chemical precipitation route, were also determined by BET and Malvern particle size analyser, respectively. The synthesized powder was soaked in stimulated body fluid (SBF) medium for various periods of time in order to evaluate its bioactivity. The changes of $\mathrm{pH}$ of SBF medium were measured. High bioactivity of prepared HAP powder due to the formation of apatite on its surface was observed.
\end{abstract}

Keywords. Snail shell; hydroxyapatite; calcination; $\beta$-tricalcium phosphate; bioactivity.

\section{Introduction}

Hydroxyapatite $\left[\mathrm{Ca}_{10}\left(\mathrm{PO}_{4}\right)_{6}(\mathrm{OH})_{2}\right]$ based bioceramics are successfully used as implants as they are chemically similar with the inorganic constituent of biological hard tissue (Layrotte et al 1998). It is present in bone, teeth and tendons to give these organs stability, hardness and function. On account of its chemical similarity with the biological calcified tissue it is remarkably biocompatible (Li et al 1992). Due to the formation of strong bond with the hard tissue, it is widely used in orthopedics or in dental implants.

HAP is also a potential implant material due to its excellent osteoconductive properties (de Groot 1900; Jarcho 1981). HAP has been shown to stimulate osteoconduction and is a material that can be integrated into bone without provoking an immune reaction. The biological response to HAP implants is influenced by its properties. The application of HAP as useful biocompatible materials largely depends on the purity and morphology of the powder. HAP can be prepared by different routes like chemical precipitation, sol-gel route, combustion synthesis, plasma etc (Roy and Linnehan 1974; Young and Holcomb 1982; Brown and Fulmer 1991; Partenfelder et al 1991; Brendel et al 1992; Arita et al 1995). The purity in the final HAP powder and stoichiometry (molar

(anjuvan@gmail.com) ratio of $\mathrm{Ca} / \mathrm{P}=1.67$ ) can be well controlled by the chemical precipitation route. The different chemical processes use precursors like $\mathrm{Ca}\left(\mathrm{NO}_{3}\right)_{2}, \mathrm{Ca}(\mathrm{OH})_{2}$ etc as the source of calcium[Ca] and $\left(\mathrm{NH}_{4}\right)_{2} \mathrm{HPO}_{4}, \mathrm{H}_{3} \mathrm{PO}_{4}$ etc as the source of phosphorus $[\mathrm{P}]$ during synthesis of HAP. The extremely pure HAP powder is very expensive and needs high quality precursors. Most of the sources of $\mathrm{Ca}^{2+}$ contain different types and levels of impurities mainly silica. Snail shell consists of $\mathrm{CaCO}_{3}$ with minor amount of $\mathrm{MgCO}_{3}$ and other matters can be potential precursors for the production of HAP.

The composition of human bone is an inorganic/organic hybrid consisting of $70 \%$ (wt) apatitic calcium phosphates and 30\% (wt) organic (largely collagen) (Cowin et al 1987). The apatitic calcium phosphate of bone mineral consists of carbonate, small amount of sodium, magnesium and other trace elements. The submicroscopic crystals of calcium phosphates in bone resemble the crystal structure of synthetic HAP (Sinha et al 2001).

The objective of the present paper is to synthesize pure and biocompatible HAP using snail shell as precursor following chemical precipitation method (Jarcho 1978). The powders are characterized using XRD, DTA/TGA, FTIR, SEM and BET surface area. Hydroxyapatite prepared by precipitation route also has the feature of small size, low crystallinity and high surfacial activation which can meet different demands (Liu et al 2001).

Keeping the above points in mind, the present study was aimed to produce and enhance the bioactivity of stoichiometric 
HAP prepared from garden snail shell, Helix aspersa and to evaluate its bioactivity in simulated body fluid.

\section{Experimental material and methods}

Garden snail shells (SS) were collected and their shell covering was removed carefully. Shells were washed with tap water followed by distilled water to remove the mud, sand and other impurities. The cleaned shells were dried in direct sunlight for 2 days. Dry and cleaned SS were calcined at $1000^{\circ} \mathrm{C}$ for $2 \mathrm{~h}$ so that all organic matters and proteins escaped out. The calcined SS was treated with concentrated nitric acid to convert it to $\mathrm{Ca}\left(\mathrm{NO}_{3}\right)_{2} .130 \mathrm{ml}$ of $1.63(\mathrm{~N})$ ammonical $\mathrm{Ca}\left(\mathrm{NO}_{3}\right)_{2}$ solution was added drop wise to a mixture of ammonical $\left(\mathrm{NH}_{4}\right)_{2} \mathrm{HPO}_{4}$ solution with constant stirring with the help of a magnetic stirrer. The $\mathrm{pH}$ of the solution was maintained at 10 . Hydroxyapatite was formed as per the following reaction:

$$
\begin{aligned}
& 10 \mathrm{Ca}\left(\mathrm{NO}_{3}\right)_{2}+6\left(\mathrm{NH}_{4}\right)_{2} \mathrm{HPO}_{4}+2 \mathrm{H}_{2} \mathrm{O} \\
& \quad \rightarrow \mathrm{Ca}_{10}\left(\mathrm{PO}_{4}\right)_{6}(\mathrm{OH})_{2}+12 \mathrm{NH}_{4} \mathrm{NO}_{3}+8 \mathrm{HNO}_{3} .
\end{aligned}
$$

The resulting suspension was boiled for $10 \mathrm{~min}$ and cooled in an ice bath overnight to obtain a white gelatinous precipitate. The precipitate was filtered and filtered cake (residue) was dried in an oven at $80^{\circ} \mathrm{C}$. The dried sample of hydroxyapatite was ground to powder.

The thermal analysis of the snail shell was performed by NETZSCH-Geratebau GmbH Thermal Analyser at a heating rate of $10^{\circ} \mathrm{C} / \mathrm{min}$ from ambient to $1200^{\circ} \mathrm{C}$ to study the weight loss and thermal behaviour. The powder samples of SS, calcined SS and synthesized HAP samples were examined with high resolution X-ray diffractometer (PW-1830, Philips, The Netherlands) using $\mathrm{Cu}-\mathrm{K} \alpha$ radiation. The $\mathrm{X}$-ray diffraction $(\mathrm{XRD})$ patterns were recorded in steps of $0.01^{\circ}$ interval with $1 \mathrm{~s}$ counting time at each step. Fourier transform infrared (FTIR) spectrum of synthesized HAP powder was obtained over the wave numbers $400-4500 \mathrm{~cm}^{-1}$. The powder was dispersed into pellets of $\mathrm{KBr}$ (mixed in 1:4 ratio) and the spectra was recorded with a Perkin-Elmer (S2000) IR spectrometer. The particle size analysis of HAP was done by Malvern Particle Size Analyzer (Model - Micro-P, UK). The surface morphology of SS and the prepared HAP powder were studied by scanning electron microscope (SEM) while the surface area of the prepared HAP samples was determined with BET surface area analyser (QUANTACHROME Model:Autosorb1).

\subsection{In vitro bioactivity evaluation}

The in vitro bioactivity evaluation of synthesized HAP powder from garden snail shell was performed in a stimulated body fluid (SBF) media of $\mathrm{pH} 7.4$ at a ratio of $1 \mathrm{mg} / \mathrm{ml}$ in a water bath at $37^{\circ} \mathrm{C}$. The changes in the $\mathrm{pH}$ of SBF medium were measured at pre-determined time intervals using a $\mathrm{pH}$ meter. Scanning electron microscopy (SEM) was used to identify the apatite formation on surface of the samples and to evaluate the surface morphology of the samples after immersion in SBF medium for 7, 14 and 21 days, respectively.

\subsection{Preparation of synthetic body fluid}

SBF is known to be a metastable buffer solution (Neuman and Neuman 1958; Ohtsuki et al 1992) and even a small, undesired variance in both of the preparation steps and storage temperatures, may drastically affect the phase purity and high-temperature stability of the produced HA powders, as well as kinetics of precipitation processes.

Merck grade $\mathrm{NaCl}$ (99.5\%), $\mathrm{NaHCO}_{3}(99.5 \%), \mathrm{KCl}$ (99.0\%), $\left(\mathrm{Na}_{2} \mathrm{HPO}_{4}\right) \cdot 2 \mathrm{H}_{2} \mathrm{O}(99 \cdot 5 \%),\left(\mathrm{MgCl}_{2}\right) \cdot 6 \mathrm{H}_{2} \mathrm{O}$ (99.0\%), $\mathrm{Na}_{2} \mathrm{SO}_{4},\left(\mathrm{CH}_{2} \mathrm{OH}\right)_{3} \mathrm{CNH}_{2}(99.5 \%), \mathrm{CaCl}_{2} \cdot \mathrm{H}_{2} \mathrm{O}(99.0 \%)$ and $\mathrm{HCl}$ (37 vol\%, Carlo-Erba, Rome, Italy) were used in the preparation of SBF.

SBF solutions (Nakanishi et al 1993; Kangasniemi et al 1994a, b) were prepared by dissolving appropriate quantities of the above chemicals in deionized water. Reagents were added, one by one after each reagent was completely dissolved in $700 \mathrm{ml}$ of water, in the order given in table 1 . A total of $40 \mathrm{ml}$ of $1 \mathrm{M} \mathrm{HCl}$ solution was consumed for $\mathrm{pH}$ adjustments during the preparation of 11 of SBF solutions. A $15 \mathrm{ml}$ aliquot of this acid solution was added just before the addition of the sixth reagent, viz. $\left(\mathrm{CaCl}_{2}\right) \cdot 2 \mathrm{H}_{2} \mathrm{O}$. Otherwise, the solution would display slight turbidity. The remaining part of the $\mathrm{HCl}$ solution was used during subsequent titration. Following the addition of eighth reagent (tris(hydroxymethyl) aminomethane), the solution temperature was raised from ambient to $37^{\circ} \mathrm{C}$. This solution was then titrated with $1 \mathrm{M}$ $\mathrm{HCl}$ to a $\mathrm{pH}$ of 7.4 at $37^{\circ} \mathrm{C}$. During the titration process, the solution was also continuously diluted with consecutive additions of de-ionized water to make the final volume equal to 1 l. It was observed in this study that the prepared SBF solutions can be stored at $5^{\circ} \mathrm{C}$ for a month without degradation.

\subsection{Biodegradation test}

Biodegradation test of calcined HAP prepared from garden snail shell, Helix aspersa, was done by taking tris- $\mathrm{HCl}$ buffer solution. 0.05 $\mathrm{M}$ tris-HCl solution was prepared using distilled water. $\mathrm{pH}$ of solution was maintained at 7.4 at $37^{\circ} \mathrm{C}$

Table 1. Chemical composition of SBF solutions.

\begin{tabular}{llc}
\hline Order & \multicolumn{1}{c}{ Reagent } & Amount (gpl) \\
\hline 1. & $\mathrm{NaCl}$ & $6 \cdot 547$ \\
2. & $\mathrm{NaHCO}_{3}$ & $2 \cdot 268$ \\
3. & $\mathrm{KCl}$ & $0 \cdot 373$ \\
4. & $\left(\mathrm{Na}_{2} \mathrm{HPO}_{4}\right) 2 \mathrm{H}_{2} \mathrm{O}$ & $0 \cdot 178$ \\
5. & $\mathrm{MgCl}_{2} \cdot 6 \mathrm{H}_{2} \mathrm{O}$ & $0 \cdot 305$ \\
6. & $\mathrm{CaCl}_{2} \cdot 2 \mathrm{H}_{2} \mathrm{O}$ & $0 \cdot 368$ \\
7. & $\mathrm{Na}_{2} \mathrm{SO}_{4}$ & $0 \cdot 071$ \\
8. & $\left(\mathrm{CH}_{2} \mathrm{OH}\right)_{3} \mathrm{CNH}_{2}$ & $6 \cdot 057$ \\
\hline
\end{tabular}

Patent pending. “Turkish Patent Institute," Turkey, Appl. No. 990037, 11 January 1999. 
by adding $1 \mathrm{M} \mathrm{HCl}$. Calcined HAP in the form of pellets were soaked in tris- $\mathrm{HCl}$ buffer solution for one week and then the samples were dried at $100{ }^{\circ} \mathrm{C}$ and final weight loss of sample was determined by the formulae as given below

$$
\% \text { Weight loss }=\frac{W_{1}-W_{2}}{W_{2}} \times 100,
$$

where $W_{1}$ is the initial weight of sample and $W_{2}$ the final weight of sample after soaking in tris- $\mathrm{HCl}$ solution.

\section{Results and discussion}

\subsection{DTA/TGA of snail shell (SS)}

DTA/TGA analysis of snail shell showed weight loss at temperature between 90 and $120^{\circ} \mathrm{C}$ that is due to the physically adsorbed water (figure 1). Over a wide range of temperature from $250-400{ }^{\circ} \mathrm{C}$ the weight loss is due to the decomposition of $\mathrm{MgCO}_{3}$ combined with the combustion of hydrocarbons. The weight loss along with endothermic peak at $750-850{ }^{\circ} \mathrm{C}$ indicates the decomposition of $\mathrm{CaCO}_{3}$ following the reaction

$$
\mathrm{CaCO}_{3} \rightarrow \mathrm{CaO}+\mathrm{CO}_{2} \uparrow
$$

So it is confirmed from the thermal analysis that snail shell mainly contains $\mathrm{CaCO}_{3}$ along with small amount of $\mathrm{MgCO}_{3}$ and other organic matters.

\subsection{XRD analysis}

A typical XRD profile of SS and calcined SS HAP has been shown in figure 2. The raw SS showed presence of $\mathrm{CaCO}_{3}$ phase, whereas $\mathrm{CaO}$ was detected in the calcined snail shell.

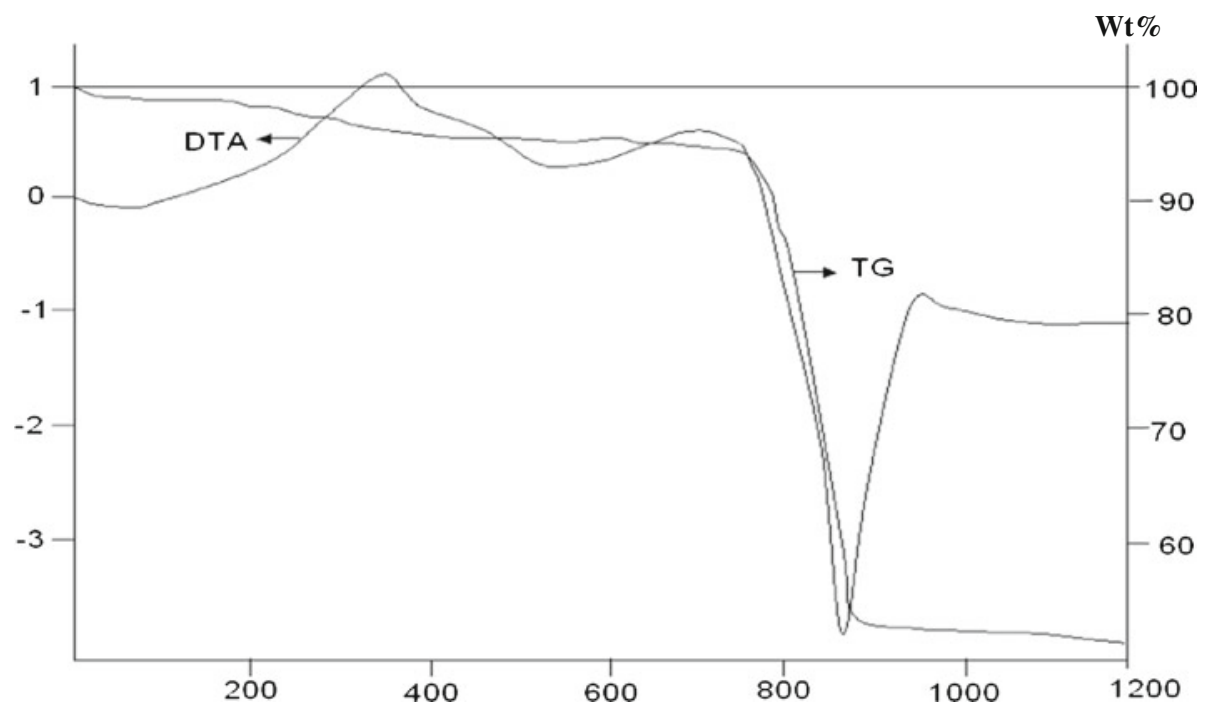

Figure 1. TGA/DTA analysis of as dried snail shell.

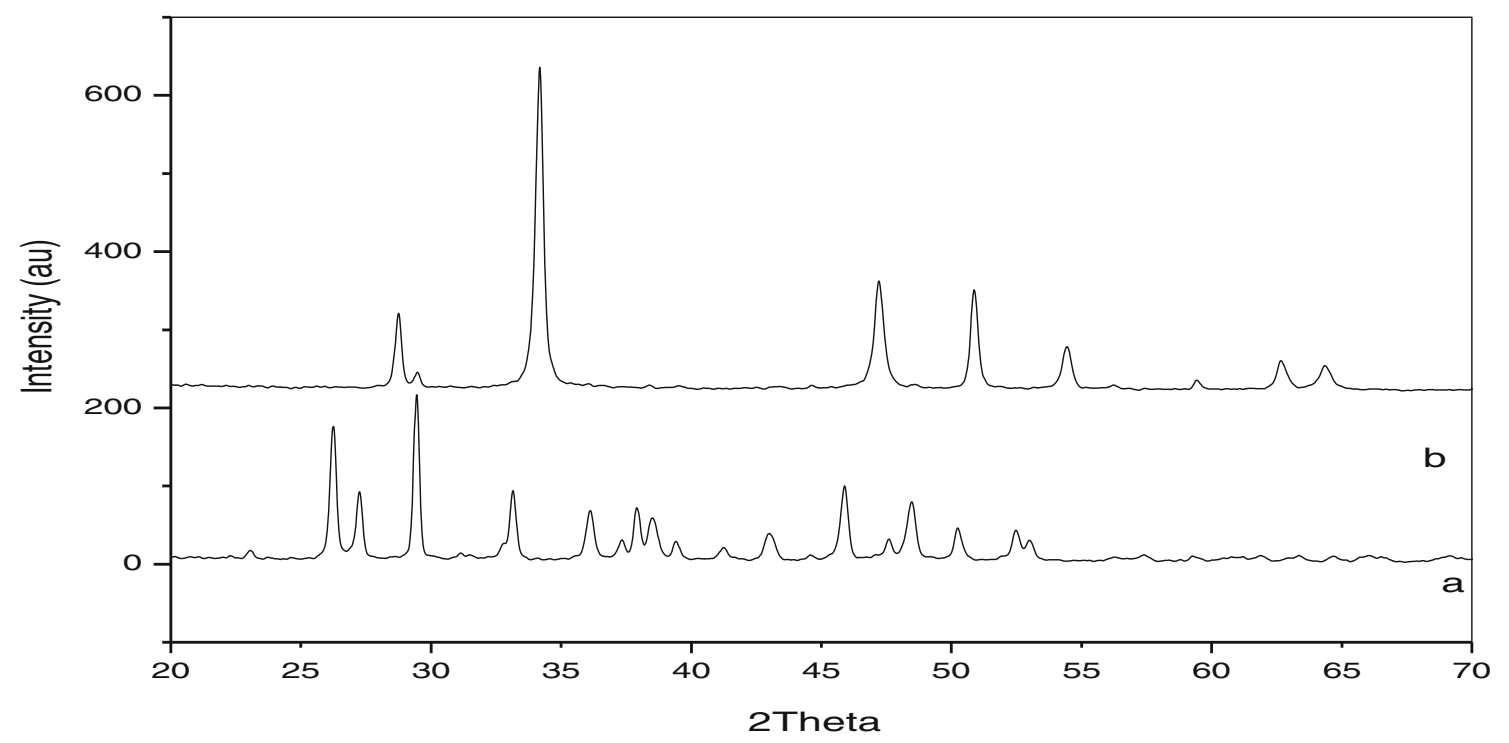

Figure 2. XRD patterns of a. snail shell and b. calcined snail shell at $1000^{\circ} \mathrm{C} / 2 \mathrm{~h}$. 
The appearance of calcined SS was soft, porous and white in colour. However, due to delay in recording, some amount of $\mathrm{CaO}$ was converted to $\mathrm{Ca}(\mathrm{OH})_{2}$ by adsorbing moisture from the atmosphere which is depicted in figure $2 b$.

XRD phase analysis of HAP powder has been shown in figure 3. Three high-intensity peaks located at $2 \theta=31.7^{\circ}$, $32.2^{\circ}$ and $32.9^{\circ}$ with $\mathrm{Cu} \mathrm{K} \alpha$ radiation are difficult to be exactly recognized from their diffraction patterns. XRD patterns reveal the formation of HAP and it well resembles with the standard JCPDS file. The unindexed peak at $30.75^{\circ}$ (figure 3b) may be due to $\beta$-tricalcium phosphate which indicates the initiation of conversion of HAP to $\beta$-tricalcium phosphate on heating HAP above $800^{\circ} \mathrm{C}$. The calcined HAP exhibits well crystallized sharp peaks of characteristics HAP. The HAP powders, thus synthesized from snail shell precursor, are very pure and chemical analysis of powders confirms the same observation.

\subsection{FTIR analysis}

Infrared characterization was carried out on the sample to study the spectral characteristics indicative of the chemical bonding in the synthesized HAP powder. The spectrum (figure 4) can be divided into four regions with peaks having wave numbers around $3500,1420,1100$ and $600 \mathrm{~cm}^{-1}$. The

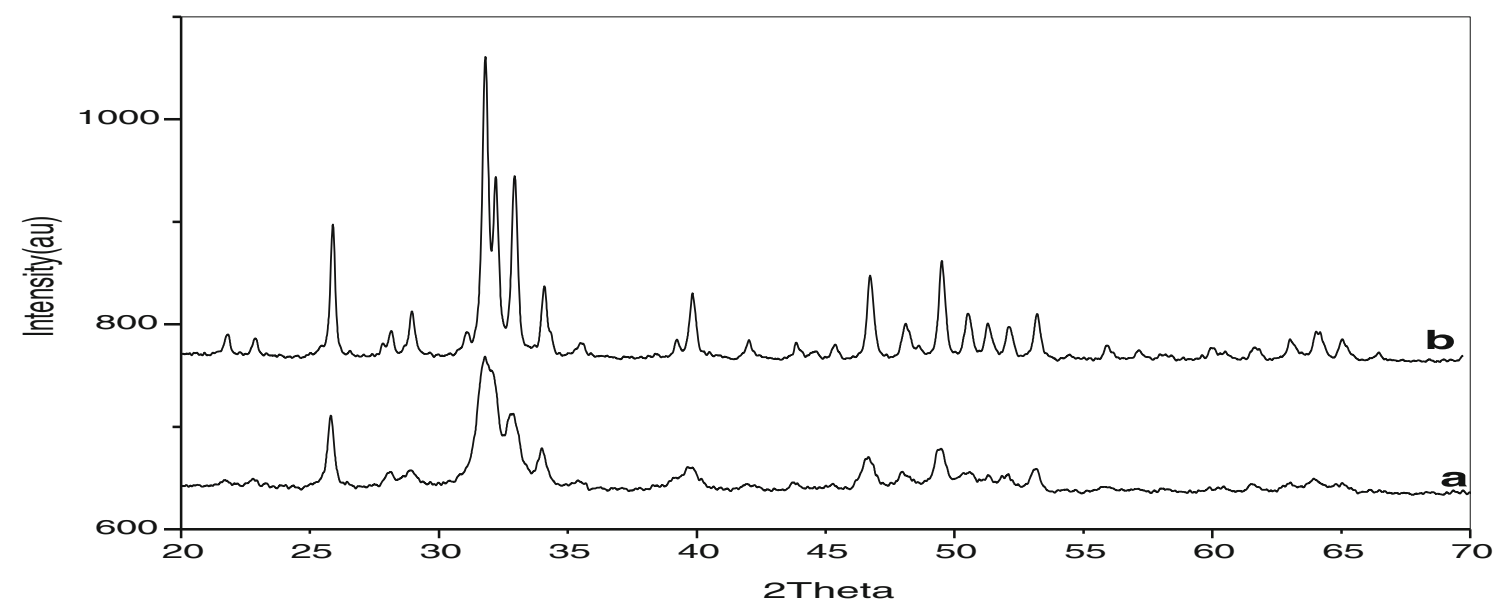

Figure 3. XRD pattern of a. HAP (synthesized) and b. calcined HAP (synthesized) at $800^{\circ} \mathrm{C} / 2 \mathrm{~h}$.

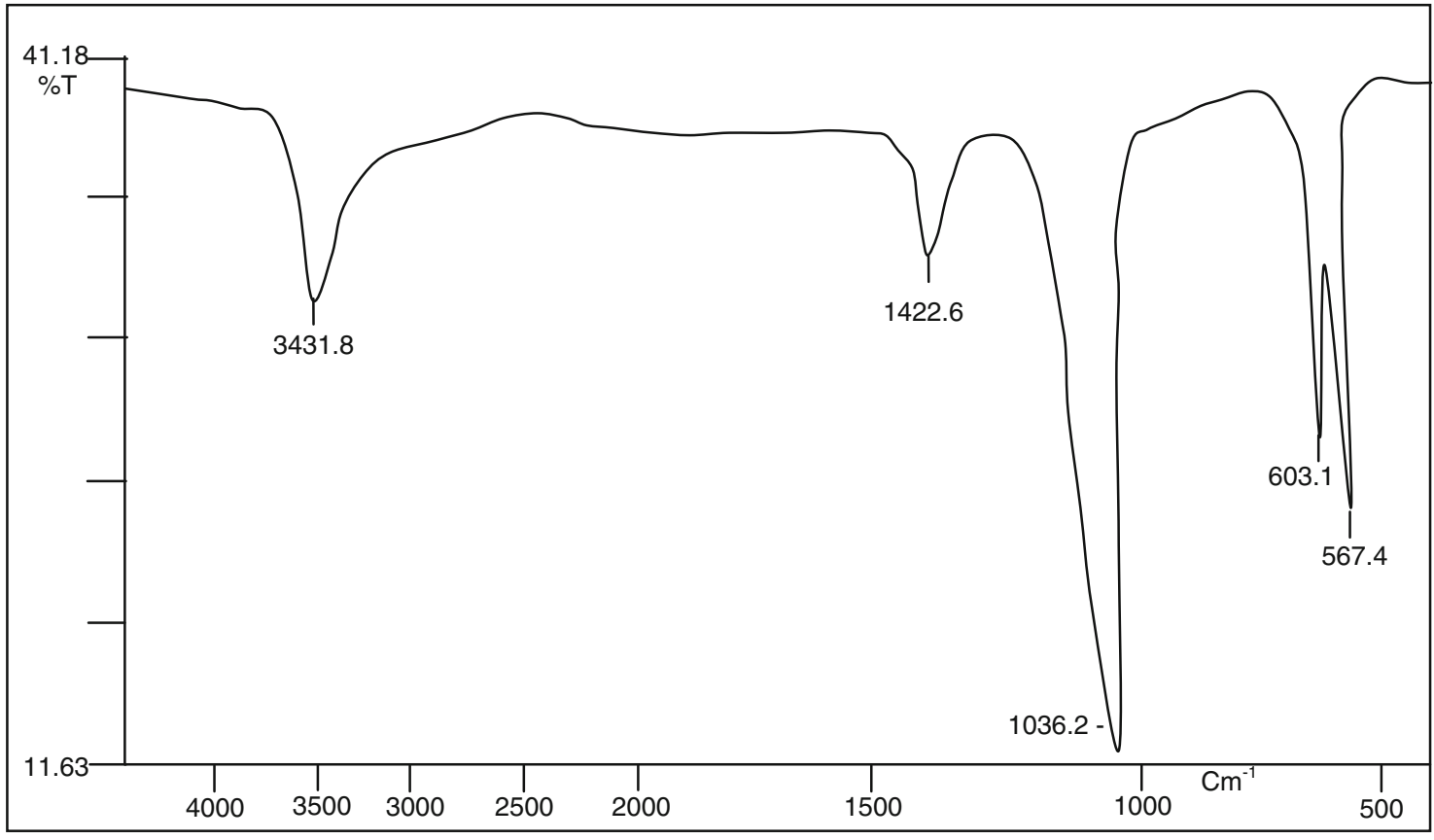

Figure 4. FTIR spectrum of HAP powder. 
peak observed around $3431.8 \mathrm{~cm}^{-1}$ is due to the presence of -OH bond (Russell et al 1996). This peak is mainly due to O-H stretching vibration in HAP (Sargin et al 1997). The peak at $1036 \cdot 2 \mathrm{~cm}^{-1}$ is associated with the stretching modes of the P-O bonds of HAP (Sargin et al 1997; Ramanan and Ramannan 2004). The double peak at $603.1 \mathrm{~cm}^{-1}$ and $567.4 \mathrm{~cm}^{-1}$ are due to bending modes of $\mathrm{P}-\mathrm{O}$ bonds in phosphate groups (Ramanan and Ramannan 2004). Thus, the presence of $\mathrm{PO}_{4}^{3-}$ group in HAP is almost confirmed from IR studies. $\mathrm{pH}$ of the medium during synthesis of HAP was maintained using ammonium solution and it was removed from the suspension with repeated washing with distilled water. In spite of all efforts to remove ammonia from the solution, there is a possibility of small amount of it in the HAP powder. The IR analysis shows a small broad peak at $1422.6 \mathrm{~cm}^{-1}$; which is characteristics peak of $\mathrm{NH}_{4}^{+}$-group (Tas 2000; Gomez-Morales et al 2001; Caroline et al 2002).

\subsection{Particle size analysis}

Particle size analysis of HAP powder was carried out following laser technique and pattern of particle size distribution is plotted in figure 5. Average particle size was found to be $2.63 \mu \mathrm{m}$. Small amount of fine particles $(0 \cdot 2-0 \cdot 3 \mu \mathrm{m})$ are also present in the synthesized powder.

\subsection{Surface area measurement}

The surface areas of the hydroxyapatite powder and calcined HAP determined are 83 and $15 \mathrm{~m}^{2} / \mathrm{g}$, respectively. Powders are agglomerated during calcinations; but HAP powders have to be calcined to remove volatile impurities like ammonia.

\subsection{Scanning electron microscope (SEM)}

The morphologies of as synthesized and calcined HAP powders are shown in figure 6. Uncalcined HAP powders are almost regular and round in shape; whereas calcined HAP powders are agglomerated. The microstructure as revealed from SEM is well in agreement with the particle size analysis and BET surface area analyser results.

\subsection{Bioactivity evaluation}

SEM micrographs of the surfaces of the immersed HAP powder after soaking in SBF for various periods of time are shown in figure 7 . It is clear from figure 7 that tiny agglomerated bone like apatite particles are formed on the surface of HAP powder soaked for different periods of time (7, 14 and 21 days, respectively). Initially, the ideal body condition i.e. $37^{\circ} \mathrm{C}$ and $\mathrm{pH}, 7 \cdot 4$, was maintained prior to the introduction of HAP in SBF solution. The change in $\mathrm{pH}$ was measured at regular time intervals from 0 to 21 days by $\mathrm{pH}$ meter. Figure 7(b) shows SEM micrograph of HAP soaked in SBF for 14 days. As the soaking time was increased from 7 to 14 days the number and size of the agglomerated particles also increased. The increase of agglomerated particles is evident due to the formation of apatite or mineralization being taking place on the surface of HAP. Figure 7(c) shows SEM micrograph of HAP soaked in SBF for 21 days. It is clear from the SEM analysis that with increase in soaking time there was increase in number and size of particles on the surface of HAP. The results indicated that the synthesized HAP powder from garden snail shell showed high bioactivity in SBF solution.

The change in $\mathrm{pH}$ of the $\mathrm{SBF}$ solution was recorded and it was noticed that the $\mathrm{pH}$ of $\mathrm{SBF}$ solution changes with

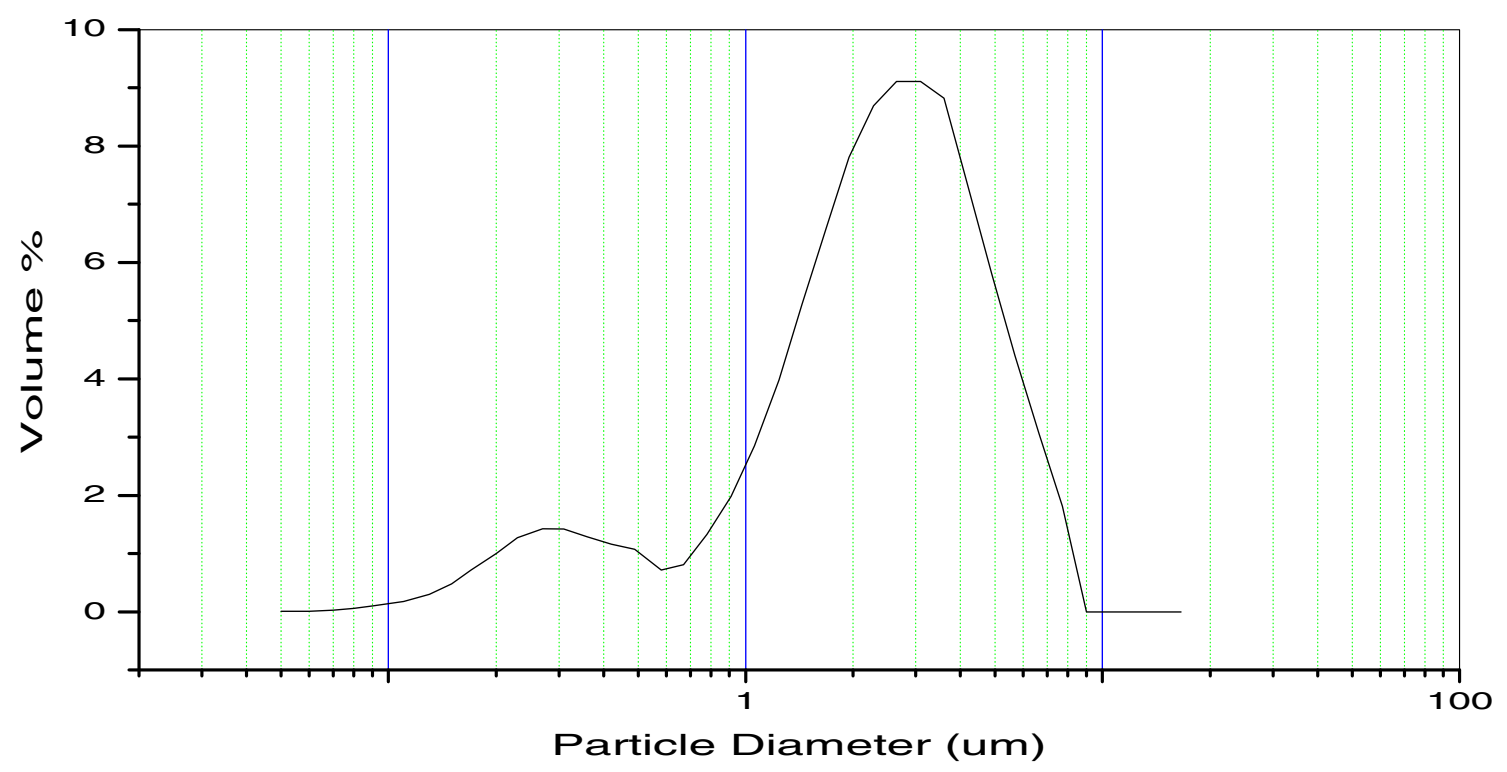

Figure 5. Particle size analysis of HAP powder. 

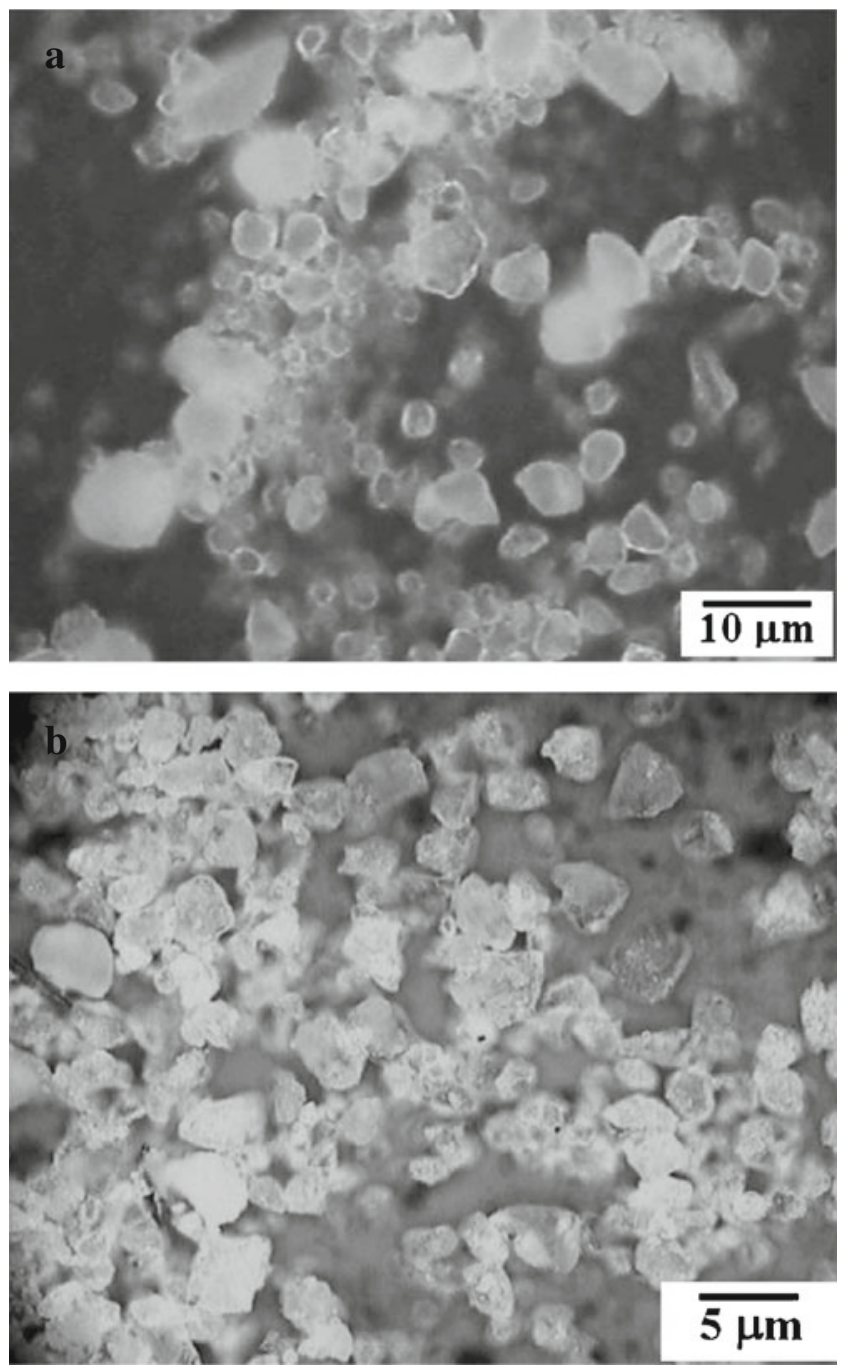

Figure 6. SEM micrograph of (a) synthesized HAP powder and (b) calcined $\left(850^{\circ} \mathrm{C} / 2 \mathrm{~h}\right) \mathrm{HAP}$ powder.

increase in soaking time. A change in $\mathrm{pH}$ from 7.4 to 7.33 was recorded from 0 days to 21 days, respectively.

The possible explanation for the above can be given as the formation of apatite due to the electrostatic interaction on the HAP surface due to calcium ions and phosphate ions present in SBF. Figure 8 describes bone-like apatite formation on HAP in SBF which can be summarized as follows: (i) there is formation of two precursors i.e. Ca-rich ACP (figure 8(a)) and Ca-poor ACP (figure 8(b)) leading to the formation of apatite (figure 8(c)) on the surface of HAP, (ii) the surface of HAP after being soaked in SBF acquires negative charge by exposing hydroxyl and phosphate ions on the surface of HAP, (iii) the negative charge present on the surface of HAP attracts positive charged calcium ions from SBF to form large number of Ca-rich ACP on the surface of HAP, (iv) this positive charge Ca-rich ACP interacts with the negative charge phosphate ions present in SBF to form Ca-poor ACP. The result is the formation of apatite on
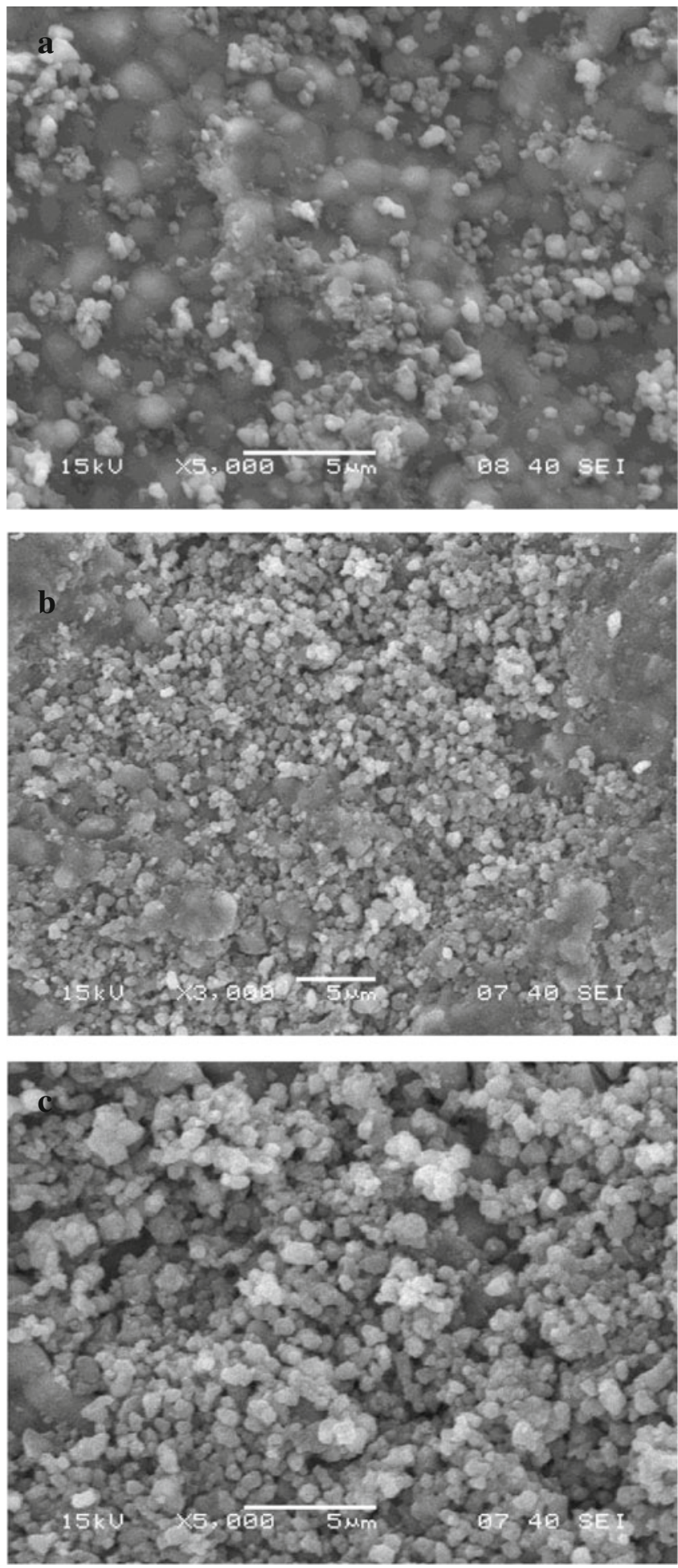

Figure 7. SEM micrographs of (a) surfaces of synthesized HAP powders after soaking in SBF for 7 days, (b) surfaces of synthesized HAP powders after soaking in SBF for 14 days and (c) surfaces of synthesized HAP powders after soaking in SBF for 21 days.

the surface of HAP (Williamson and Hall 1953; Hench and Wilson 1993; Murugan and Ramakrishna 2005) and (v) therefore, once formed on a bioactive surface in SBF 


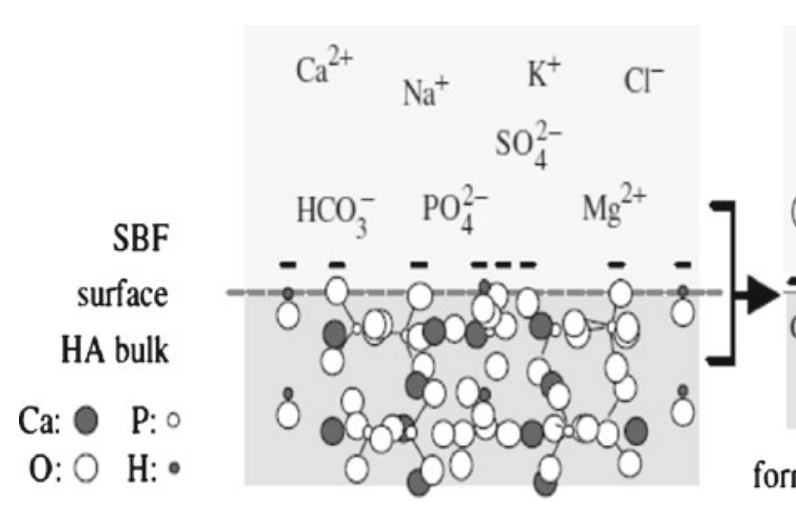

(a)

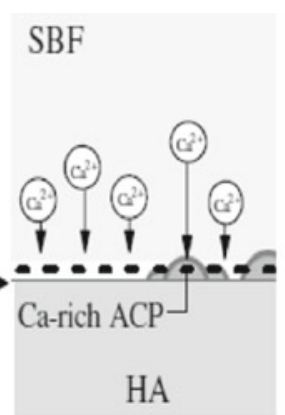

formation of Ca-rich ACP formation of Ca-poor ACP

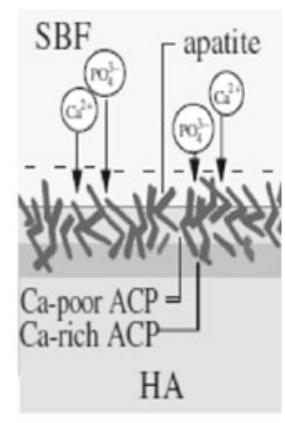

formation of apatite

(d)

Figure 8. (a) Represents negative charge on surface of HAP, (b) formation of Ca-rich ACP on surface of HAP, (c) formation of Ca-poor ACP on surface of HAP and (d) formation of apatite on surface of HAP.

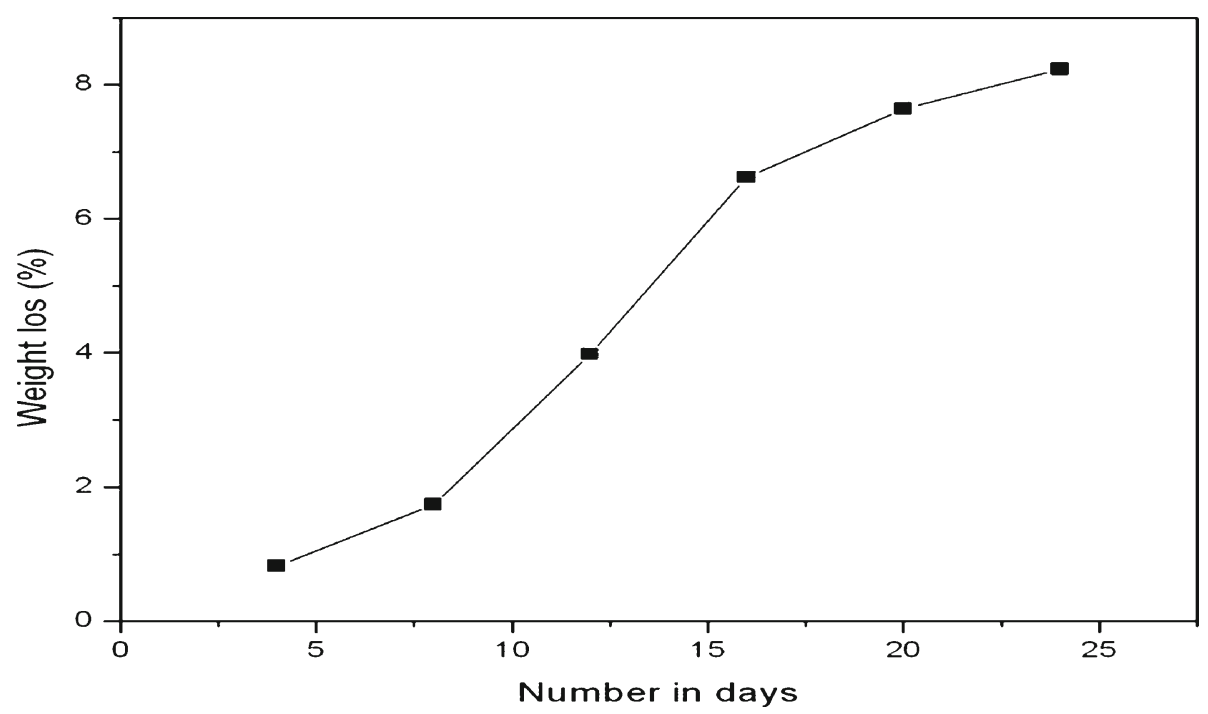

Figure 9. Change in weight loss with increase in number of days.

the apatite grows spontaneously, consuming calcium and phosphate ions and incorporating sodium, magnesium and carbonate ions thereby revealing bone mineral like compositional and structural features.

\subsection{Biodegradation of HAP in synthetic body fluid}

Figure 9 shows variation in degradation of porous HAP with increase in number of days. It is clear from the figure that there is increase in weight loss with increase in number of days. The degradability value of HAP after 21 days reached to $5 \%$. The synthesized HAP has a great in vitro activity similar to that of biological apatite which could have great impact on implant cell interaction in a body environment. The surface of HAP exhibits dissolution couples with mineralization. The results indicated that the synthesized HAP powder from garden snail shell (Helix aspersa) showed high bioactivity in SBF solution.

\subsection{In vitro biodegradation}

Biodegradation of calcined HAP samples in the form of pellets were carried out in tris- $\mathrm{HCl}$ solution. HAP samples were soaked in tris-buffer solution at $\mathrm{pH} 7.4$ and a temperature of $37^{\circ} \mathrm{C}$ for 7 days (Kokubo and Takadama 2006). When HAP pellets were soaked in tris-buffer solution, the loss of calcium ion took place which resulted in the increase in $\mathrm{pH}$ of the buffer from 7.4 to 8.2 which confirms the biodegradation of HAP. The amount of calcium leached out during the process was calculated to be $2 \%$. Thus it appears that the ageing time in tris- $\mathrm{HCl}$ solution may also affect the weight loss behaviour. 


\section{Conclusions}

A stoichiometric, pure and thermally stable hydroxyapatite powder was synthesized from snail shell (Helix aspersa) by chemical precipitation method. XRD analysis indicated phase purity and crystallinity of hydroxyapatite powder. TG/DTA result showed that snail shell is mainly composed of calcium carbonate $\left(\mathrm{CaCO}_{3}\right)$. Fine particle size of hydroxyapatite was produced. The present work is based on the utilization of biological waste (snail shell) to produce hydroxyapatite for bio-medical applications. The increase of agglomerated particles is evident of formation of apatite or mineralization being taking place on the surface of HAP. The results indicated that the synthesized HAP powder from garden snail shell showed high bioactivity in SBF solution. The change in $\mathrm{pH}$ of the SBF solution was recorded and it was noticed that the $\mathrm{pH}$ of SBF solution increases with increase in soaking time. The prepared HAP powder showed high bioactivity similar to that in biological apatite and higher bioactivity in comparison with conventional HAP. Thus, prepared HAP from garden snail shell (Helix aspersa) might be more useful for treatment of oral bone defects in comparison with conventional HAP, and might be more effective as a bone replacement material to promote bone formation.

An attempt will be made in future to synthesize porous HAP and study its bio-compatibility. Mass production of biocompatible HAP for biological application may be possible at simple and low cost through this route.

\section{References}

Arita I H, Wilkinson D S, Mondragon M A and Castano V M 1995 Biomaterials 16404

Brendel T, Engel A and Russel C 1992 J. Mater. Sci.: Mater. Med. 3175

Brown P W and Fulmer M 1991 J. Am. Ceram. Soc. 74934
Caroline E, Victoria E and Gnanam F D 2002 Trends Biomater. Artif. Organs 1612

Cowin S C, Vanburskirk W C and Ashaman R B 1987 Handbook of bioengineering (eds) R Skalak and C Schien (New York: McGraw Hill)

de Groot K 1900 Biomaterials 147

Gomez-Morales J, Torrent-Burgues J, Boix T, Fraile J and Rodriguez-Clemente R 2001 Cryst. Res. Technol. 3615

Hench L L and Wilson J 1993 An introduction to bioceramics (London: World Scientific Publishing Co. Ltd.) 2nd ed.

Jarcho M 1978 U.S. Patent 4097935

Jarcho M 1981 Clin. Orthop. Rel. Res. 157259

Kangasniemi I, de Groot K and Kokubo T 1994a J. Am. Ceram. Soc. 121307

Kangasniemi I, de Groot K, Kokubo T and Yli-Urpo A U 1994b J. Non-Cryst. Solids 6281

Kokubo T and Takadama H 2006 Biomaterials 272907

Layrotte P, Ito A and Tateishi T 1998 J. Am. Ceram. Soc. 811421

Li P, Ohtsuki C, Kokubo T, Nakanishi K, Soga N, Nakamura T and Yamamuro T 1992 J. Am. Ceram. Soc. 752094

Liu Changsheng, Huang Yue, Shen Wei and Cui Jinghua 2001 Biomaterials 22301

Murugan R and Ramakrishna S 2005 J. Cryst. Growth 274209

Nakanishi K, Kokubo T and de Groot K 1993 Biomaterials 8963

Neuman W and Neuman M 1958 The evolution of media effects (Chicago: University of Chicago Press) p. 34

Ohtsuki C, Kokubo T and Yamamuro T 1992 J. Non-Cryst. Solids 14384

Partenfelder U M E, Engel A and Russel C A 1991 J. Mater. Sci.: Mater. Med. 4292

Ramanan S R and Ramannan V 2004 Mater. Lett. 583320

Roy D M and Linnehan S K 1974 Nature 247220

Russell S W, Luptak K A, Suchicital C T A, Alford T L and Pizziconi V B 1996 J. Am. Ceram. Soc. 79843

Sargin Y, Kizilyalli M, Telli C and Guler H 1997 J. Eur. Ceram. Soc. 17963

Sinha A, Ingle A, Munim K R, Vaidya S N, Sharma B P and Bhisey A N 2001 Bull. Mater. Sci. 24653

Tas A C 2000 Biomaterials 211429

Williamson G K and Hall W H 1953 Acta Metall Sinica 122

Young R A and Holcomb D W 1982 Calcified Tissue Int. 3417 